\title{
Developing a Method of Calculating the Operational Flow of Methanol to Prevent the Formation of Crystalline Hydrates in the Operation of Underground Gas Storage Facilities
}

\author{
Anton Shipovalov ${ }^{1}$, Alexey Gladenko ${ }^{2}$, Ivan Seroshtanov ${ }^{3}$, and Anton Ryabkov, ${ }^{4}{ }^{*}$ \\ ${ }^{1,3}$ Gazprom Transgaz Yugorsk, st. Mira 15, Yugorsk, Russia \\ ${ }^{2}$ Omsk State Technical University, st. Mira 11, Omsk, Russia \\ ${ }^{4}$ Industrial University of Tyumen, 625001 Volodarskogo str. 38, Tyumen, Russia
}

\begin{abstract}
When operating underground storage (UGS) of gas hydrates liquidation formed untimely could lead to serious consequences - a complete shut-in and elimination of its process. With a small fund operating wells with high daily output storage operation would entail a violation of technological regime, the failure of gas sales plans, increased hours of downtime operational fund. Therefore, ensuring the smooth and reliable operation of underground gas storage wells fund is an urgent task. The authors of the article developed a methodology for calculating the operational flow of methanol to prevent the formation of gas hydrates in UGS operation. On the basis of the developed technique using industrial operating data Punginskoye UGS made the study of technological modes of its work and recommendations to prevent hydrate formation in the underground gas storage wells.
\end{abstract}

\section{Introduction}

In production systems, processing and transportation of natural gas the formation of crystalline hydrates is a serious problem associated with the violation of technological processes working gas production equipment and pipelines. Typical locations of gas hydrate formation in field conditions are: a near-wellbore zone of wells, cables and infield collectors.

To restore the normal operation of the well after the occurrence of operational complications serious measures to thawing of long hydrate blockage are required. For the realization of these measures considerable forces and means are spent, but one can't stop hydrate formation in gas wells completely. Unlike gas deposits the characteristic feature of the operation of underground gas storage facilities (UGS) is the cyclical nature of the UGS work, when there is a periodic change in the direction of gas flow - from the formation (in

\footnotetext{
* Corresponding author: an100980@,rambler.ru
} 
season selection) into the reservoir (in the injection season). Under these operating conditions, the formation of hydrates, most often occurs in the gas sampling period from the formation at negative outdoor air temperature and higher sampling rates. Season selection is usually carried out from October to March, sometimes to the April.

\section{The object of research}

In field conditions the most common way to deal with hydrates is the use of volatile hydrate inhibitor - methanol. Methanol has a high degree of temperature reduction of hydrate formation, the ability to rapidly decompose already formed tube and mix with water in any ratio. It has low viscosity and low freezing point $[3,17]$. The advantage of using methanol as the non-hydrate reactant is that this technology provides not only the prevention of hydrate formation, but under certain conditions, is an effective means to remove already formed deposits of hydrate.

Using the unique physical and chemical properties of methanol, in particular its ability to be mixed in any concentration and pass into the vapor phase without losing its initial characteristics, and the cyclic operation of the underground storage mode (injection of gas into the reservoir - the selection of the gas from the formation [19]) the technology of methanol supply in injection period in the bottom zone of the formation of individual wells was developed. Its technological mode of operation is accompanied with the formation of hydrates in the selection period. In practice, this warning method of providing of continued non-hydrate well operation is much more effective than the elimination methods of the already arisen problem.

The technology provides a method of methanol injection into the formation before the end of the season of filling gas storage $[14,16,18]$. Submission of hydrate inhibitor occurs in the flow of gas wells, technological mode of operation which is characterized as a hydrate. At the stage of technology development it is found out that it is necessary to deliver methanol to the bottom hole of wells for one - two months before the end of the gas injection season at UGS.

\section{Methods}

Currently there are various methods for calculating the parameters of technology using methanol [1, 2, 5, 6, 7, 8]. The works of the authors V.A.Istomin, V.G.Kvon, B.V.Degtyarev, Y.F.Makogon, E.B.Buhgalter, G.V.Ponomarev and others are well-known.

There is a method for calculating VNIIGAZ methanol consumption, which in accordance with the WFD 39-1.13-010-2000 involves calculation of hydrate formation temperature and indirectly reflects the influence of the gas composition [10, 20]. This technique is very effective for the calculation of indices in a continuous supply of methanol.

When the periodic injection into the reservoir with the change of the operating conditions it is necessary to create flexible methodologies for incorporating changes in the conditions, frequency of injection, methanol concentration and the relationship between process parameters [4].

To develop a new method which would allow to remove the hydrate problem securely and have the least possible negative consequences and measures to ensure the smooth operation of the gas transportation system, industrial researches in different technological modes UGS were carried out.

Initial data for calculation are adopted by dispatching data Punginskoye UGS operation. The composition of gases corresponds to average over a five year period and is identified as Gas №1 (Cenomanian), Gas №2, Gas №3 (Valanginian). 
Underground storage of gas hydrates can be formed directly in the formation, if injection is conducted in the cooled aquifer [4]. Hydrates are accumulated directly in the bottomhole formation zone or at a considerable distance from the well bottom, if the hightemperature gas is injected under pressure, greatly exceeding the initial hydrostatic pressure [15].

The estimated dependence for determining the specific consumption of methanol injected into the gas stream to prevent hydrate formation in the "protected" area, is [2]:

$$
G=\left(\Delta W \cdot C_{2}\right) /\left(C_{1}-C_{2}\right)+\left[\left(100-C_{2}\right)\right]\left(q_{g 1}-q_{g 2}+q_{c 1}+q_{c 2}\right),
$$

where $\Delta \mathrm{W}$ - the amount contained in the gas (or condensate) liquid water, $\mathrm{kg} / 1000 \mathrm{~m} 3$;

$\mathrm{C} 2$ - minimum necessary concentration of methanol in the aqueous phase required to prevent hydrate formation in the protected point, $\% \mathrm{wt}$;

C1 - methanol concentration in the injected gas (90 - 95\% wt.);

qg1 - amount of methanol contained in the feed gas, $\mathrm{kg} / 1000 \mathrm{~m} 3$;

$\mathrm{qg} 2$ - methanol, dissolving in the gas phase at a concentration in the aqueous solution $\mathrm{C} 2, \mathrm{~kg} / 1000 \mathrm{~m} 3$;

qc1 - the amount of methanol contained in the feed gas hydrocarbon condensate, $\mathrm{kg} /$ $1000 \mathrm{~m} 3$;

qc2 - the amount of methanol, dissolved in the hydrocarbon condensate at a concentration of water-methanol solution $\mathrm{C} 2, \mathrm{~kg} / 1000 \mathrm{~m} 3$.

The resulting image, depending on the flow rate of methanol pressure and temperature, as shown in [1], with a high correlation coefficient can be described by an equation of the form (for 60 to $75 \mathrm{kgf} / \mathrm{cm} 2$ pressure and gas temperature of 0 to $20^{\circ} \mathrm{C}$ ):

$$
G=N \cdot \ln p-0,064 \cdot t-M
$$

where $\mathrm{p}$ - pressure, $\mathrm{kgf} / \mathrm{cm} 2 ; \mathrm{t}$ - temperature, ${ }^{\circ} \mathrm{C} ; \mathrm{N}$ and $\mathrm{M}$ - factors that depend on the composition of the gas.

This dependence can be used to calculate the daily consumption of methanol by gas pressure for various compositions.

The technique of methanol consumption calculation, suggested by IUT, is based on the obtained inhibitor, depending on the pressure and consumption of gas composition at its constant flow rate [9]:

$$
Q_{24}=N \cdot \ln p-M
$$

where $\mathrm{N}$ and $\mathrm{M}$ - coefficients which depend on gas composition.

This dependence can be used to calculate the daily consumption of methanol by pressure directly to the different gas compositions. Example of dependence obtained for different gases is shown in Figure 1.

Obviously, the pressure increases [13] and, consequently, the temperature of hydrate formation, increasing the daily intake of methanol. On consumption of methanol, based on the received graphic dependence, the gas composition affects. With increase in the proportion of heavy hydrocarbons in the gas, methanol consumption curve depending on the pressure becomes steeper, it indicates a sharp, compared with methane, methanol consumption increases with increasing pressure $[11,12]$. 


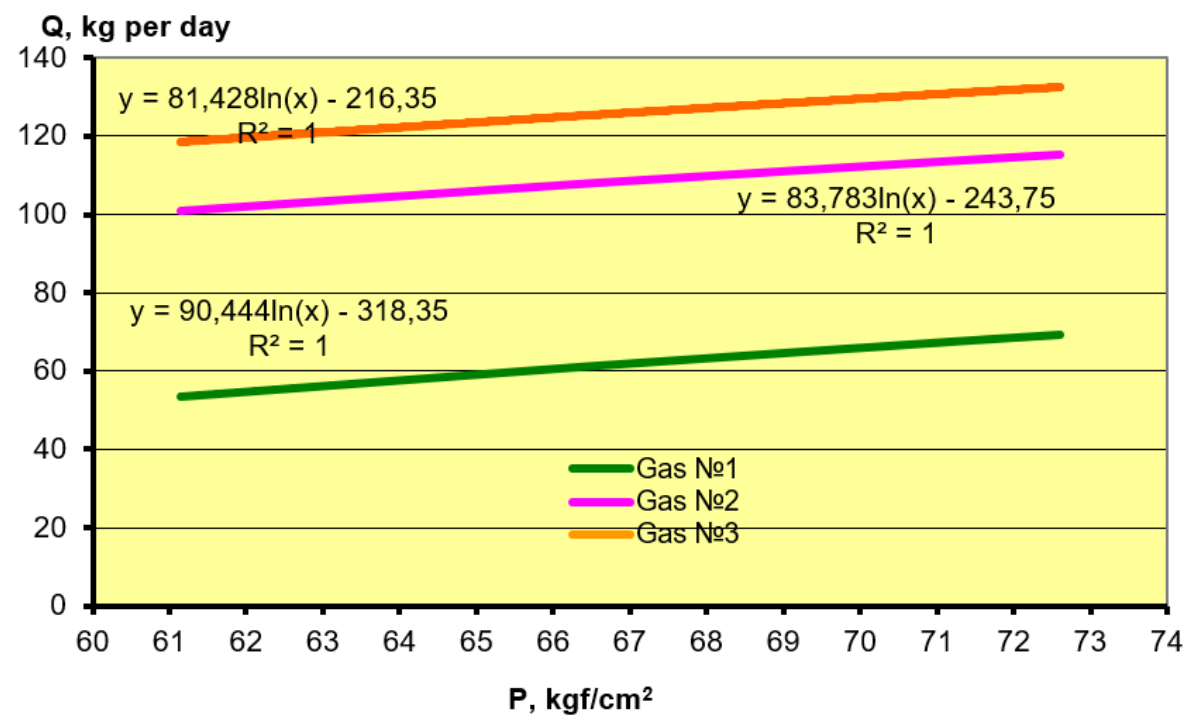

Fig. 1. The dependence of the methanol flow from the pressure and gas composition.

The dependence of the daily consumption of methanol from the gas composition can be expressed in terms of the coefficient B, which depends on the specific gravity. Changing the value of the coefficient $\mathrm{B}$ in the original model of hydrate, dependence of the coefficients $\mathrm{N}$ from $\mathrm{B}$ and $\mathrm{M}$ from $\mathrm{B}$ is obtained.

The authors obtained dependence according to the definition:

- The ratio $\mathrm{N}$ from $\mathrm{B}$ :

$\mathrm{N}=63,83 \mathrm{e} 0,017 \mathrm{~B}$,

- The ratio $\mathrm{M}$ from $\mathrm{B}$ :

$\mathrm{M}=0,215 \mathrm{~B} 2+9,755 \mathrm{~B}+37,27$.

To determine the daily consumption of methanol at a constant gas flow rate of the proposed method, it is necessary to know the pressure and determine the coefficient $\mathrm{B}$, depending on the specific gravity $\gamma_{\Gamma}^{\prime}$, the concept, suggested by G.V.Ponomarev.

The concept of the specific gravity is the following one. The equilibrium conditions depend on the existence of hydrates in gas composition, which can be roughly characterized by a molecular or specific gravity. If we calculate the sum of the partial specific weights hydrate forming components $\sum Y_{i}{ }^{\prime} \gamma_{i}{ }^{\prime}$ which are a part of the gas, and divide it by the amount of mole hydrate forming components $\sum Y_{i}$, the resulting value $\gamma_{\Gamma}^{\prime}$ will characterize gas hydrate-forming ability more strictly:

$$
\gamma_{\mathrm{g}}^{\prime}=\frac{\sum Y_{i}^{\prime} \cdot \gamma_{i}^{\prime}}{\sum \mathrm{Y}_{\mathrm{i}}^{\prime}} .
$$

Analytical dependence for determining the coefficient B $\left(0.555<\gamma^{\prime} \leq 1\right)$ is based on the analysis of data obtained in UIT:

$$
B=\frac{1,73}{\left(\gamma_{g}^{\prime}-0,5\right)^{0,8}}+7,8
$$


where $\gamma^{\prime} \mathrm{g}$ - reduced specific gravity.

The proposed relationship considerably simplifies finding the coefficient method in the calculation of the daily consumption of methanol.

Table 1 shows the values of coefficients for the gas №1 … №3.

Table1. Value ratios $\mathrm{N}$ and $\mathrm{M}$.

\begin{tabular}{lccc}
\hline & $\mathrm{B}$ & $\mathrm{N}$ & $\mathrm{M}$ \\
\hline Gas №1 & 24.25 & 0.552 & 1.744 \\
Gas №2 & 15.7 & 0.471 & 0.860 \\
Gas №3 & 14 & 0.458 & 0.706 \\
\hline
\end{tabular}

To determine the amount of methanol, required for the injection before selection period, the following dependence is suggested:

$$
Q_{I}=\frac{Q_{24} T_{I}}{C K_{E}}
$$

where QI - the amount of methanol for well injection;

C - methanol concentration;

$\mathrm{TI}$ - methanol supply frequency;

$\mathrm{KE}$ - the coefficient, characterizing the effectiveness of the inhibitor for the period between the methanol supply.

\section{Results and discussion}

The resulting methanol dependence on the daily consumption of gas flow is shown in Figure 2-4.

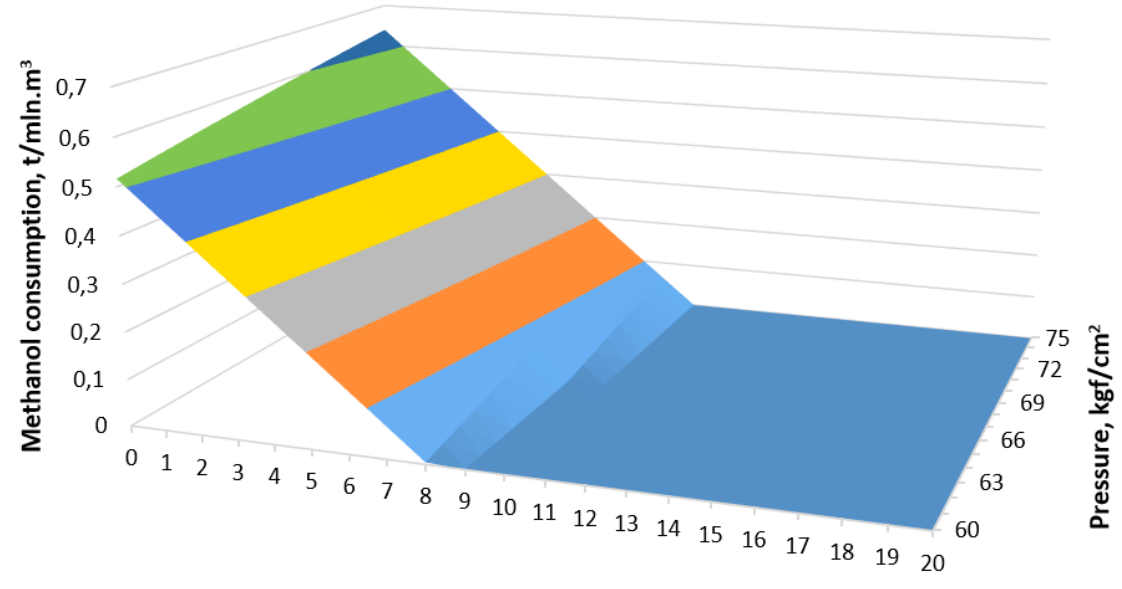

Temperature, ${ }^{\circ} \mathrm{C}$

$\because 0-0,1=0,1-0,2=0,2-0,3 \quad \square 0,3-0,4 \quad \square 0,4-0,5=0,5-0,6 \quad 0,6-0,7$

Fig. 2.The graph of methanol consumption dependence from the pressure and temperature for the gas №1. 


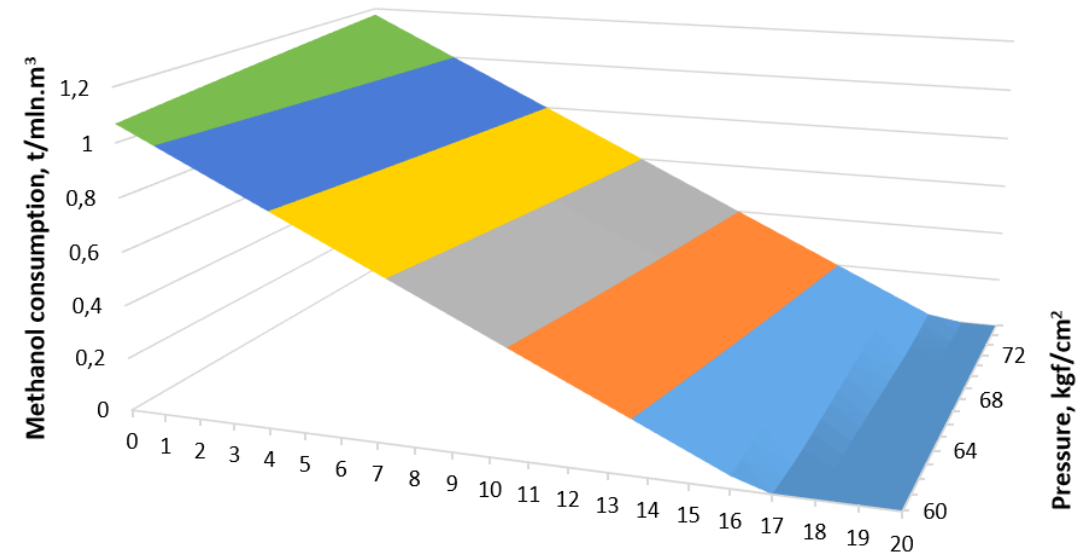

Temperature, ${ }^{\circ} \mathrm{C}$

$\square 0-0,2=0,2-0,4=0,4-0,6=0,6-0,8 \quad \square 0,8-1=1-1,2$

Fig. 3. The graph of methanol consumption dependence from the pressure and temperature for the gas №2.

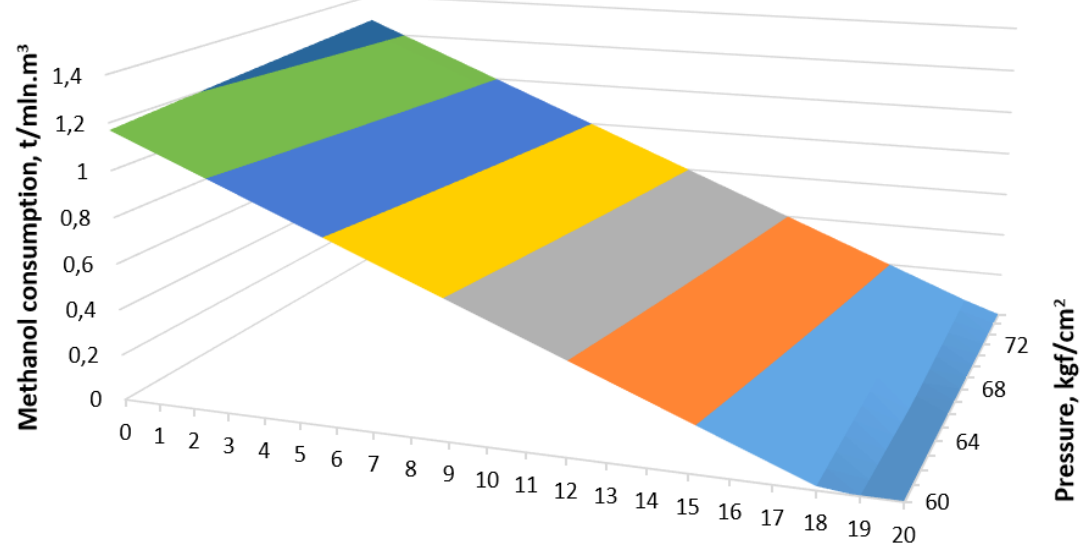

Temperature, ${ }^{\circ} \mathrm{C}$

$\varpi 0-0,2=0,2-0,4=0,4-0,6=0,6-0,8=0,8-1=1-1,2=1,2-1,4$

Fig. 4. The graph of methanol consumption dependence from the pressure and temperature for the gas №3.

We see that when increasing the proportion of heavy hydrocarbons in the gas, the dependence of methanol consumption from the gas flow increases due to the higher temperature of hydrate formation and, consequently, the greater minimum necessary concentration of methanol in the water phase which is required to prevent hydrate formation in the protected point.

Thus, according to the analysis of the developed technique for modeling of hydrate formation process in the conditions of UGS Punginskoye, heavy gas is more dangerous. A large amount of methanol is necessary to prevent its hydrating. 


\section{Conclusion}

1. A method of preventing hydrate formation has been developed. It has been successfully tested in operation mode UGS of "pumping gas", by supplying methanol to the culling of problem wells, the operation of which has been complicated by hydrate formation in wellhead and ground communications.

2. It has been found that reliable non-hydrated modes of wells and pipelines on UGS are implemented with sufficient content of methanol in the whole volume of gas withdrawn from the storage. Methodology for calculation of the specific consumption of methanol to each non-hydrated well operation provides a certain margin of methanol feed, since the temperature drop at the end of the loop, the appearance of the produced water in the well production affect its consumption.

3. It has been found that for the calculation of the time and period of the methanol injection into the reservoir it is necessary to know exactly the start of the upcoming season selection. An ideal variant is methanol feed during the entire period of the injection season in problem wells. It requires additional feasibility study and may lead to a large reagent costs. It has been found that the positive effect of the methanol injection is achieved in 1-2 months before the start of the withdrawal season, i.e., start of processing bottom-hole zones - in August - September.

\section{References}

1. A. Shipovalov, Yu. Zemenkov, S. Toropov, M. Zemenkova, S. Podorozhnikov, I. Tyrylgin, V. Pavlov, Aspects of technological reliability and economic efficiency of operation of underground storages of natural gas of Western Siberia (TSOGU, Tyumen, 2012)

2. WFD 39-1.13-010-2000 Instruction on calculation of methanol consumption standards for the use in the calculation of the maximum permissible or temporarily agreed discharges of methanol for the facilities of "Gazprom"

3. S. Dudin, Yu. Zemenkov, A. Shipovalov, S. Podorozhnikov, Oil and gas, 2, 65-69 (2011)

4. S. Dudin, V. Nekrasov, Yu. Zemenkov, Mining informational and analytical bulletin (scientific and technical journal), 3, 53-61 (2013)

5. V. Istomin, V. Kwon, Prevention and elimination of gas hydrates in gas production systems (Ltd "Gazprom RPI", Moscow, 2004)

6. V. Istomin, V. Yakushev, V. Kwon, S. Dolgaev, Hydrate technologies (VNIIGAZ, Moscow, 2009)

7. Y. Makogon, A. Malyshev, A. Sedykh, Y. Shalyaho, K. Topchev, K. Unarokov, Temporary instruction about the prevention and elimination of hydrates in gas production and transportation systems (VNIIGAZ, Moscow, 1983)

8. Yu. Zemenkov, Backup energy for the reliability of the gas supply system (TSOGU, Tyumen, 2006)

9. A. Shipovalov, Yu. Zemenkov, S. Podorozhnikov, M. Zemenkova, Pipeline transportation: Theory and Practice, 6, 25-28 (2010)

10. A. Shipovalov, Yu. Zemenkov, A. Smirnov, S. Podorozhnikov, Pipeline transportation: Theory and Practice, 1, 27-30 (2011)

11. K. Voronin, Yu. Zemenkov, Oil and gas, 3, 70-72 (2012)

12. K. Voronin, V. Pavlov, Yu. Zemenkov, Oil and Gas Terminal: Proceedings of the International scientific conference, 169-173 (2015)

13. K. Voronin, Natural and Technical Sciences, 5, 208-211 (2011) 
14. V. Nekrasov, R. Levitin, Fundamental and applied research: Problems and results, 13, 223-228 (2014)

15. V. Nekrasov, R. Levitin, A. Maier, Oil and gas, 5, 63-65 (2014)

16. V. Nekrasov, R. Levitin, Yu. Zemenkov, Equipment and technologies for oil and gas complex, 3, 43-46 (2014)

17. Yu. Zemenkov, V. Shpilevoy, S. Podorozhnikov, A. Zakirzakov, Energotechnological complexes at the design and operation of transport and storage facilities of hydrocarbons (TSOGU, Tyumen, 2014)

18. K.Voronin, S. Dudin, M. Zemenkova, N. Zakirov, A. Gladenko, Modern problems of science and education, 2-3, 32 (2015)

19. K. Voronin, A. Gladenko, S. Sokolov, M. Chekardovsky, Modern problems of science and education, 2-3, 31 (2015)

20. M. Zemenkova, T. Puzina, S. Maslakov, I. Seroshtanov, V. Nikiforov, Mining informational and analytical bulletin (scientific and technical journal), 4, 174-183 (2014) 